\title{
Purification and Characterization of Aporphine Alkaloids from Leaves of Nelumbo nucifera Gaertn and Their Effects on Glucose Consumption in 3T3-L1 Adipocytes
}

\author{
Chengjun Ma ${ }^{1}$, Jinjun Wang ${ }^{1}$, Hongmei Chu ${ }^{2}$, Xiaoxiao Zhang ${ }^{1}$, Zhenhua Wang ${ }^{1}$, \\ Honglun Wang ${ }^{3}$ and Gang $\mathrm{Li}^{1,3, *}$
}

1 School of Life Science, Yantai University, 30 Qinquan Road, Yantai 264005, China; E-Mails: chengjun-ma@163.com (C.M.); wangjinjun19890522@163.com (J.W.); mfsaih67@163.com (X.Z.); zhenhuawang@tom.com (Z.W.)

2 School of Pharmacy, Yantai University, 30 Qinquan Road, Yantai 264005, China; E-Mail: chu_hong_mei@sina.com

3 Key Laboratory of Tibetan Medicine Research, Northwest Institute of Plateau Biology, Chinese Academy of Sciences, Xining 810001, China; E-Mail: hlwang@nwipb.cas.cn

* Author to whom correspondence should be addressed; E-Mail: lgleegang@sohu.com; Tel./Fax: +86-535-6902-638.

Received: 5 December 2013; in revised form: 28 January 2014 / Accepted: 28 January 2014 / Published: 26 February 2014

\begin{abstract}
Aporphine alkaloids from the leaves of Nelumbo nucifera Gaertn are substances of great interest because of their important pharmacological activities, particularly anti-diabetic, anti-obesity, anti-hyperlipidemic, anti-oxidant, and anti-HIV's activities. In order to produce large amounts of pure alkaloid for research purposes, a novel method using high-speed counter-current chromatography (HSCCC) was developed. Without any initial cleanup steps, four main aporphine alkaloids, including 2-hydroxy-1-methoxyaporphine, pronuciferine, nuciferine and roemerine were successfully purified from the crude extract by HSCCC in one step. The separation was performed with a simple two-phase solvent system composed of $n$-hexane-ethyl acetate-methanol-acetonitrile-water $(5: 3: 3: 2.5: 5, v / v / v / v / v)$. In each operation, $100 \mathrm{mg}$ crude extracts was separated and yielded $6.3 \mathrm{mg}$ of 2-hydroxy-1-methoxyaporphine (95.1\% purity), $1.1 \mathrm{mg}$ of pronuciferine (96.8\% purity), $8.5 \mathrm{mg}$ of nuciferine (98.9\% purity), and $2.7 \mathrm{mg}$ of roemerine $(97.4 \%)$ respectively. The chemical structure of four aporphine alkaloids are identified by means of electrospray ionization MS (ESI-MS) and nuclear magnetic resonance (NMR) analysis. Moreover, the effects of four separated aporphine alkaloids on insulin-stimulated glucose
\end{abstract}


consumption were examined in 3T3-L1 adipocytes. The results showed that 2-hydroxy-1methoxyaporphine and pronuciferine increased the glucose consumption significantly as rosiglitazone did.

Keywords: Nelumbo nucifera Gaertn; aporphine alkaloids; high-speed counter-current chromatography (HSCCC); isolation; 3T3-L1 adipocytes; glucose consumption

\section{Introduction}

Nelumbo nucifera Gaertn, commonly called lotus, is a perennial aquatic crop grown and consumed over the world, especially in China, India, Japan, Korea, South East Asia, Russia and some countries in Africa [1]. All parts of this plant, such as fruits, seeds, stamens, roots and leaves, have been used not only as a vegetable and food garnish but also as a Chinese medicine and has been compiled in Chinese Pharmacopoeia [2]. Therefore, lotus is widely cultivated and consumed as food and medicine in China. In traditional Chinese medicine, lotus leaves are used to treat hematemesis, epistaxis, hemoptysis, hematuria, hyperlipidemia and obesity [3]. Lotus leaves are also used for tea and are commercially available in China. Pharmacologies studies revealed that its major constituents are aporphine alkaloids [4-7]. In the past, many studies have been focused on the isolation and pharmacology of its alkaloids components.

Nuciferine and its analogues, 2-hydroxy-1-methoxyaporphine, pronuciferine, and roemerine (Figure 1), are four main aporphine alkaloids components of leaves of $N$. nucifera. Since the first isolation of nuciferine in 1962, these alkaloids have received considerable attention because of their reputation of chemical and biological activities including anti-HIV [8], anti-hyperlipidemic [9], anti-platelet [10], hypotensive [11], anti-oxidant [12], anti-microbial [13], anti-obesity [14,15], anti-diabetic [16], and melanogenesis inhibitory [3]. However, their pharmacological studies often suffer from the limits of sample purity and sources. To obtain pure compounds by conventional separation methods, such as using organic solvents to extract and column chromatography including silica gel, polyamide column, thin-layer chromatography (TLC), Sephadex LH-20 chromatography and high-performance liquid chromatography (HPLC) to isolate, have been used to isolate and purify aporphine alkaloids from leaves of $N$. nucifera [17-19]. However, the conventional extract and purify methods are tedious and time-consuming, requiring multiple steps, in which column chromatography requires a long time and a large volume of organic solvent, and worse still the sample are adsorbed onto the stationary phase irreversibly. As the alternative, a new technique, high-speed counter-current chromatography (HSCCC) is widely used to separate bioactive compounds from natural resources. It is a unique liquid-liquid partition chromatography technique that uses no solid support matrix so the adsorbing effects on stationary phase material and artifact formation, tailing of solute peaks and contamination can be eliminated. This technique has the maximum capacity with an excellent sample recovery and wider range of selection of solvent systems as compared to HPLC. Furthermore, it permits introduction of crude sample directly into the hollow column [20]. Table 1 summarized the difference of HSCCC and traditional methods to produce large amounts of pure alkaloid. Up to now, over 120 different alkaloid compounds from more than 30 plant species have been successfully separated [21]. 
Figure 1. Structural formulas of aporphine alkaloids from leaves of N. nucifera.

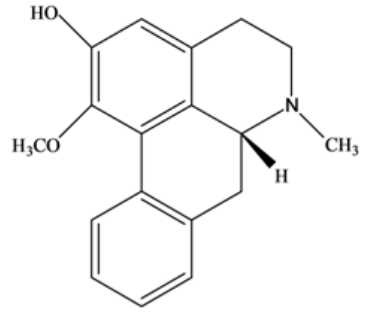

2-Hydroxy-1-Methoxyaporphine

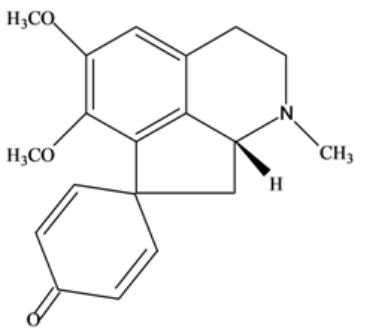

Pronuciferine<smiles>COc1cc2c3c(c1OC)-c1ccccc1C[C@]3(C)N(C)CC2</smiles>

Nuciferine

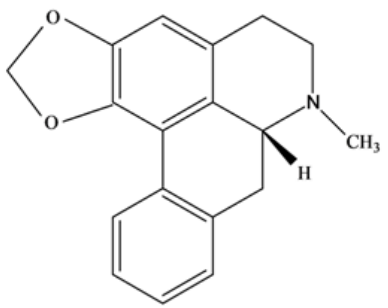

Roemerine

Table 1. The compare of high-speed counter-current chromatography (HSCCC) and the traditional methods.

\begin{tabular}{ccl}
\hline Category & HSCCC & \multicolumn{1}{c}{ Traditional Methods } \\
\hline Partition method & liquid-liquid partition & solid-liquid partition \\
Separation time & time-saving & tedious and time-consuming \\
Separation process & one step & multiple steps \\
Dosage of organic solvent & smaller volume & larger volume \\
Sample adsorbed loss & smaller & larger \\
Selection range of solvent systems & wider & limited \\
Sample condition & crude sample & multiple steps pre-treatment sample \\
\hline
\end{tabular}

It was reported that separation of three alkaloids ( $N$-nornuciferine, nuciferine and roemerine) from lotus leaves was attempted via conventional HSCCC and pH-zone-refining CCC [22], but in this study, the actual separation larger quantities of mixture by HSCCC was failed mainly due to the poor retention of the stationary phase and resulted in a poor resolution. In addition, pH-zone-refining CCC is very confusing, and thus, various parameters of the mobile phase such as solvents, $\mathrm{pH}$, and fraction ranges had to be adjusted. We have performed simple and efficient purification of four main aporphine alkaloids in lotus leaves including 2-hydroxy-1-methoxyaporphine, pronuciferine, nuciferine, and roemerine by HSCCC using an optimized two-phase solvent system. These purified alkaloids were analyzed by HPLC and chemical structures were identified by means of ESI-MS and NMR analysis. Further, insulin-stimulated glucose consumption of four separated aporphine alkaloids was measured by 3T3-L1 adipocytes. 


\section{Results and Discussion}

\subsection{Selection of Suitable Two-Phase Solvent System for HSCCC}

Suitable two-phase solvent system is the key factor for a successful HSCCC separation, which should satisfy the following three main requirements: (a) the partition coefficient $(K)$ value of the targeted compounds should be in the range of 0.5-2.0; (b) the two-phase solvents should be nearly equal volumes for each phase; and (c) the two-phase solvents should be a volatile solvent system [20,23]. In the study, the $K$ values of four alkaloids were determined in the following four solvent systems: chloroform-methanol-water, ethyl acetate-methanol-water, $n$-hexane-ethyl acetate-methanol-water, and $n$-hexane-ethyl acetate-methanol-acetonitrile-water each at various volumes (Table 2). The result indicated that the solvent systems composed of chloroform-methanol-water had a lower $K$ values $(K<0.5)$ and the systems composed of ethyl acetate-methanol-water had higher $K$ values $(K>2.0)$. These solvent compositions did not prove satisfactory as an HSCCC solvent system for our isolation and separation. When the basally solvent system composed of $n$-hexane-ethyl acetate-methanol-water was used as the two-phase solvent system, as shown in Table 1 , all $K$ values of four targeted compounds were observably improved. Based on the system, different ratios of acetonitrile were added to adjust each $K$ value to appropriate level. From the above, the two-phase solvent system composed of $n$-hexane-ethyl acetate-methanol-acetonitrile-water at a ratio of 5:3:3:2.5:5 $(v / v / v / v / v)$ was found to be the best. Under the optimized separation conditions, the isolation of four target compounds was achieved with good resolution and the retention of the stationary phase are satisfactory (57.5\%).

Table 2. The $K$ (partition coefficient) values of four alkaloids in different solvents systems.

\begin{tabular}{cccccc}
\hline \multirow{2}{*}{ Two-Phase Solvents } & \multicolumn{5}{c}{ Partition Coefficient $(\boldsymbol{K})$} \\
\cline { 2 - 6 } & Ratio $(\boldsymbol{v} / \boldsymbol{v})$ & $\mathbf{A}$ & $\mathbf{B}$ & $\mathbf{C}$ & $\mathbf{D}$ \\
\hline & $10 / 0 / 10$ & 0 & 0 & 0 & 0.01 \\
chloroform/methanol/water & $10 / 1 / 9$ & 0 & 0 & 0.01 & 0.09 \\
& $10 / 3 / 7$ & 0.02 & 0.05 & 0.10 & 0.19 \\
& $10 / 5 / 5$ & 0.07 & 0.14 & 0.25 & 0.38 \\
& $10 / 6 / 4$ & 0.04 & 0.17 & 0.21 & 0.29 \\
& $10 / 7 / 3$ & 0.02 & 0.15 & 0.18 & 0.20 \\
ethyl acetate/methanol/water & $10 / 1 / 9$ & 10.46 & 9.53 & 16.93 & 22.50 \\
& $10 / 4 / 6$ & 3.38 & 4.08 & 7.08 & 15.67 \\
& $10 / 6 / 4$ & 2.05 & 3.91 & 4.74 & 8.21 \\
m-hexane/ethyl acetate/ & $10 / 8 / 3$ & 1.71 & 3.01 & 3.89 & 7.08 \\
methanol/water & $5 / 5 / 5 / 5$ & 1.01 & 1.19 & 1.60 & 2.85 \\
& $5 / 3 / 3 / 5$ & 0.94 & 1.41 & 2.02 & 3.90 \\
& $5 / 2 / 2 / 5$ & 0.80 & 1.88 & 2.91 & 4.32 \\
$n$-hexane/ethyl acetate/ & $5 / 1 / 1 / 5$ & 1.28 & 2.69 & 3.76 & 6.54 \\
methanol/acetonitrile/water & $5 / 3 / 3 / 0.5 / 5$ & 0.89 & 1.22 & 1.74 & 3.16 \\
& $5 / 3 / 3 / 1.0 / 5$ & 0.77 & 1.03 & 1.59 & 2.44 \\
& $5 / 3 / 3 / 1.5 / 5$ & 0.69 & 0.89 & 1.42 & 2.17 \\
& $5 / 3 / 3 / 2.0 / 5$ & 0.56 & 0.77 & 1.25 & 1.94 \\
& $5 / 3 / 3 / 2.5 / 5$ & 0.51 & 0.76 & 1.20 & 1.87 \\
& $5 / 3 / 3 / 3.0 / 5$ & 0.48 & 0.66 & 1.22 & 1.79 \\
\hline
\end{tabular}

Expressed as: A: 2-hydroxy-1-methoxyaporphine; B: pronuciferine; C: nuciferine; D: roemerine. 


\subsection{HSCCC Purification and HPLC Identification}

The crude sample $(100 \mathrm{mg})$ was dissolved in $12 \mathrm{~mL}$ mixture solution of upper phase and lower phase $(1: 1, v / v)$. The sample solution was separated and purified by HSCCC according to the procedure described. The retention of the stationary phase was $57.5 \%$, and the total separation time was $500 \mathrm{~min}$. Figure 2 shows HSCCC separation of the crude extract sample, along with the HPLC chromatogram analysis of purified compounds are shown in Figure 3. Based on the HPLC analysis and the elution curve of the HSCCC (Figure 4), all collected fractions were combined into different pooled fractions. A total amount of $6.3 \mathrm{mg}$ of 2-hydroxy-1-methoxyaporphine (95.1\% purity), $1.1 \mathrm{mg}$ of pronuciferine (96.8\% purity), $8.5 \mathrm{mg}$ of nuciferine (98.9\% purity), and $2.7 \mathrm{mg}$ of roemerine (97.4\%) were yielded in one-step, respectively.

Figure 2. High-performance liquid chromatography (HPLC) chromatogram of the crude extract from the leaves of $N$. nucifera. Sample: Column: Discovery C18 column $(25 \mathrm{~cm} \times 4.6 \mathrm{~mm}, 5 \mu \mathrm{m})$; mobile phase: acetonitrile-water-triethylamine-glacial acetic acid $(55: 44: 1: 0.15, v / v / v / v)$; flow rate: $1.0 \mathrm{~mL} / \mathrm{min}$; detection wavelength: $270 \mathrm{~nm}$. A: 2-hydroxy-1-methoxyaporphine; B: pronuciferine; C: nuciferine; D: roemerine.

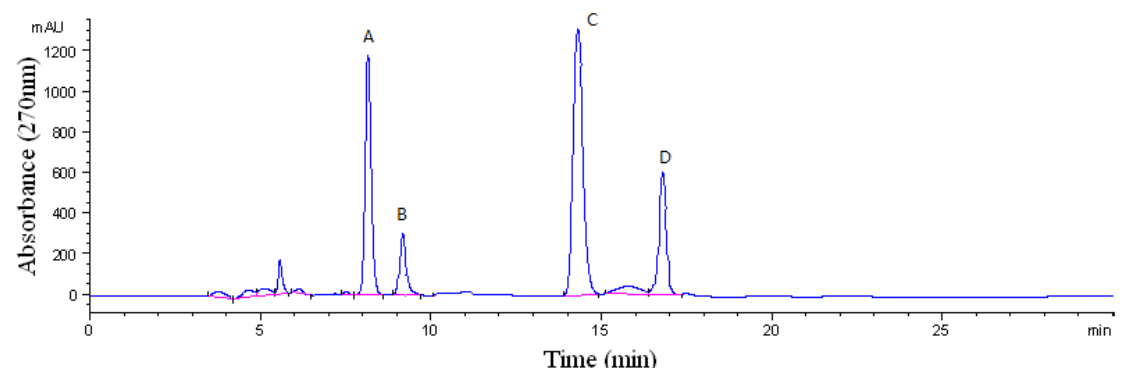

\subsection{Chemical Structure Identification}

The structural identification of 2-hydroxy-1-methoxyaporphine, pronuciferine, nuciferine, and roemerine was carried out by electrospray ionization mass spectrometry (ESI-MS), ${ }^{1} \mathrm{H}$ NMR and ${ }^{13} \mathrm{C}$ NMR spectra as follows.

Fraction A: ESI-MS $(\mathrm{m} / \mathrm{z}): 282[\mathrm{M}+\mathrm{H}]^{+} ;{ }^{1} \mathrm{H} \mathrm{NMR}\left(\mathrm{CDCl}_{3}, 400 \mathrm{MHz}\right) \delta: 8.26(\mathrm{H}, \mathrm{d}, J=8.0 \mathrm{~Hz}$, $\mathrm{OH}), 7.21 \sim 6.68(3 \mathrm{H}, \mathrm{m}, \mathrm{H}-8,9,10), 3.66\left(3 \mathrm{H}, \mathrm{s}, \mathrm{O}-\mathrm{CH}_{3}\right), 2.57\left(3 \mathrm{H}, \mathrm{s}, \mathrm{N}-\mathrm{CH}_{3}\right), 2.45(1 \mathrm{H}, \mathrm{d}, J=4.0$, $8.0 \mathrm{~Hz}, \mathrm{H}-6 \mathrm{a}) ;{ }^{13} \mathrm{C}$ NMR (100 MHz, $\mathrm{CDCl}_{3}$ ), $\delta: 143.3$ (C-1), 126.4 (C-1a), 127.8 (C-1b), 146.5 (C-2), 114.0 (C-3), 28.7 (C-4), 128.1 (C-4a), 53.5 (C-5), $43.8\left(\mathrm{~N}-\mathrm{CH}_{3}\right), 61.7$ (C-6a), 33.9 (C-7), 136.1 (C-7a), 128.1 (C-8), 126.4 (C-9), 125.8 (C-10), 127.3 (C-11), 131.8 (C-11a), $60.5\left(\mathrm{OCH}_{3}\right)$.

Fraction B: ESI-MS $(\mathrm{m} / \mathrm{z}): 312[\mathrm{M}+\mathrm{H}]^{+} ;{ }^{1} \mathrm{H} \mathrm{NMR}\left(\mathrm{CDCl}_{3}, 400 \mathrm{MHz}\right) \delta: 8.32(1 \mathrm{H}, \mathrm{d}, J=8.0 \mathrm{~Hz}$, $\mathrm{H}-12), 7.14 \sim 7.25$ (3H, m, H-8, 9,11), $6.79(1 \mathrm{H}, \mathrm{s}, \mathrm{H}-3), 3.85\left(3 \mathrm{H}, \mathrm{C}_{1}-\mathrm{OCH}_{3}\right), 3.60\left(3 \mathrm{H}, \mathrm{C}_{2}-\mathrm{OCH}_{3}\right)$, $2.61\left(3 \mathrm{H}, \mathrm{N}-\mathrm{CH}_{3}\right) ;{ }^{13} \mathrm{C} \mathrm{NMR}\left(100 \mathrm{MHz}, \mathrm{CDCl}_{3}\right), \delta: 146.2$ (C-1), 137.9 (C-1a), 150.9 (C-2), 112.1 (C-3), 29.7 (C-4), 131.1 (C-4a), 54.8 (C-5), $43.9\left(\mathrm{~N}-\mathrm{CH}_{3}\right), 31.5$ (C-6a), 38.9(C-7), 130.6 (C-7a), 128.1 (C-8), 128.9 (C-9), 206.6 (C-10), 128.3 (C-11), $126.3(\mathrm{C}-12), 56.7\left(\mathrm{OCH}_{3}\right), 60.3\left(\mathrm{OCH}_{3}\right)$. 
Figure 3. HPLC analyses of the fractions obtained by HSCCC. HPLC analysis conditions are the same as shown in Figure 2. A: 2-hydroxy-1-methoxyaporphine; B: pronuciferine; C: nuciferine; D: roemerine.

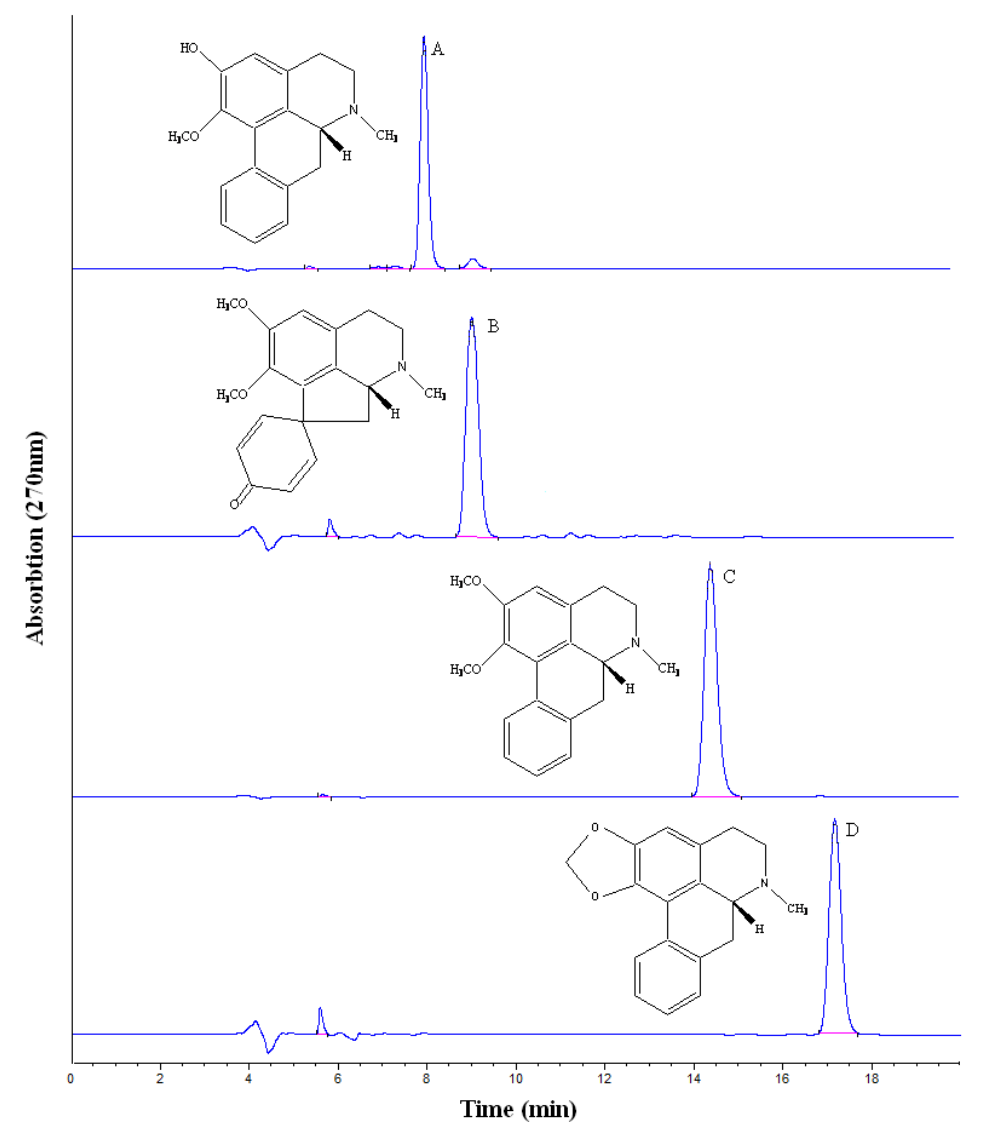

Fraction C: ESI-MS $(m / z): 296[\mathrm{M}+\mathrm{H}]^{+} ;{ }^{1} \mathrm{H}$ NMR $\left(\mathrm{CDCl}_{3}, 400 \mathrm{MHz}\right) \delta: 8.36(1 \mathrm{H}, \mathrm{d}, J=8.0 \mathrm{~Hz}$, $\mathrm{H}-11), 7.20 \sim 7.33$ (3 H, m, H-8, 9,10), $6.66(1 \mathrm{H}, \mathrm{s}, \mathrm{H}-3), 3.89\left(3 \mathrm{H}, \mathrm{s}, \mathrm{C}_{1}-\mathrm{OCH}_{3}\right), 3.66(3 \mathrm{H}, \mathrm{s}$, $\left.\mathrm{C}_{2}-\mathrm{OCH}_{3}\right), 2.59\left(3 \mathrm{H}, \mathrm{s}, \mathrm{N}-\mathrm{CH}_{3}\right) ;{ }^{13} \mathrm{C} \mathrm{NMR}\left(100 \mathrm{MHz}, \mathrm{CDCl}_{3}\right), \delta: 145.8(\mathrm{C}-1), 126.9(\mathrm{C}-1 \mathrm{a})$,

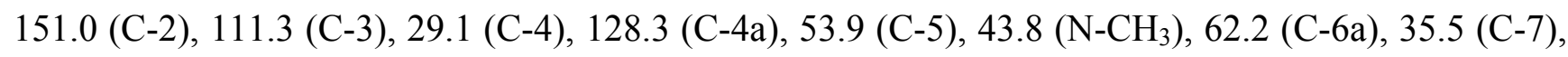
135.6 (C-7a), 127.4 (C-8), 126.6 (C-9), 126.9 (C-10), 128.2 (C-11), 132.5 (C-11a), $55.3\left(\mathrm{OCH}_{3}\right)$, $60.6\left(\mathrm{OCH}_{3}\right)$.

Fraction D: ESI-MS $(\mathrm{m} / \mathrm{z}): 280[\mathrm{M}+\mathrm{H}]^{+} ;{ }^{1} \mathrm{H}$ NMR $\left(\mathrm{CDCl}_{3}, 400 \mathrm{MHz}\right) \delta: 8.06(1 \mathrm{H}, \mathrm{d}, J=8.0 \mathrm{~Hz}$, $\mathrm{H}-11), 7.22 \sim 7.34(3 \mathrm{H}, \mathrm{m}, \mathrm{H}-8,9,10), 6.56(1 \mathrm{H}, \mathrm{s}, \mathrm{H}-3), 6.06\left(1 \mathrm{H}, \mathrm{s},-\mathrm{CH}_{2} \mathrm{O}-\right), 5.93\left(1 \mathrm{H}, \mathrm{s},-\mathrm{CH}_{2} \mathrm{O}-\right)$, $2.56\left(3 \mathrm{H}, \mathrm{s}, \mathrm{N}-\mathrm{CH}_{3}\right), 2.44(1 \mathrm{H}, \mathrm{s}, \mathrm{H}-6 \mathrm{a}) ;{ }^{13} \mathrm{C} \mathrm{NMR}\left(100 \mathrm{MHz}, \mathrm{CDCl}_{3}\right), \delta: 142.6(\mathrm{C}-1), 116.4(\mathrm{C}-1 \mathrm{a})$, 146.7 (C-2), 107.6 (C-3), 29.7 (C-4), 127.1 (C-4a), 53.7(C-5), $43.1\left(\mathrm{~N}-\mathrm{CH}_{3}\right), 62.5$ (C-6a), 34.9 (C-7), 135.2 (C-7a), 127.8 (C-8), 126.9 (C-9), 126.5 (C-10), 127.0 (C-11), 131.1 (C-11a), 100.6 (- $\left.\mathrm{CH}_{2} \mathrm{O}-\right)$.

Compared with the date given in literatures [6,22,24,25], peak A-D in Figure 1 corresponded to 2-hydroxy-1-methoxyaporphine, pronuciferine, nuciferine and roemerine. 
Figure 4. HSCCC chromatogram of crude extract from Lotus Leaf. Conditions: column: multilayer coil of $1.8 \mathrm{~mm}$ i.d.; polytetrafluoroethylene tube with a total capacity of $280 \mathrm{~mL}$; rotary speed: $850 \mathrm{rpm}$; two-phase solvent system: $n$-hexane-ethyl acetate-methanolacetonitrile-water $\quad(5: 3: 3: 2.5: 5, \quad v / v / v / v / v) ; \quad$ flow-rate: $2.0 \mathrm{~mL} / \mathrm{min}$; detection wavelength: $270 \mathrm{~nm}$; sample size: $100 \mathrm{mg}$; injection volume: $12 \mathrm{~mL}$; retention of stationary phase: 57.5\%. Peaks: A: 2-hydroxy-1-methoxyaporphine; B: pronuciferine; C: nuciferine; D: roemerine.

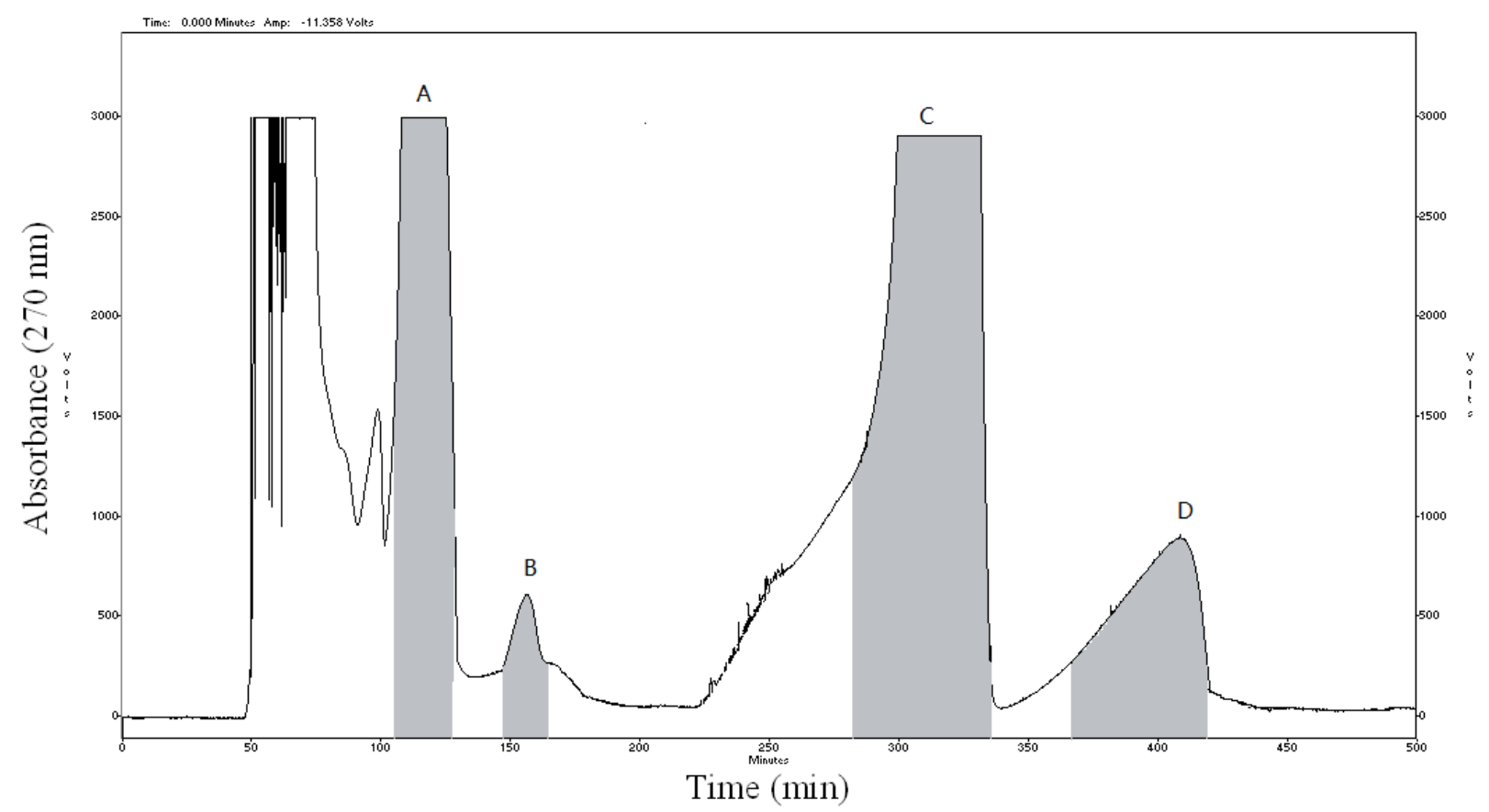

\subsection{Insulin-Stimulated Glucose Consumption of 3T3-L1 Cell}

Figure 5 showed the cytotoxicity of aporphine alkaloids $(0.5$ to $50 \mu \mathrm{g} / \mathrm{mL})$ when incubated with $3 \mathrm{~T} 3-\mathrm{L} 1$ cells for $24 \mathrm{~h}$. The survival cell was more than $95 \%$ when the compounds concentration was $2 \mu \mathrm{g} / \mathrm{mL}$. When pre-adipocytes differentiate into adipocytes, the morphological alterations are induced by the presence of oil droplets in the cytoplasm; it also leads to simultaneously increase in both glucose uptake and lipid accumulation [26,27]. As shown in Figure 6, all the four compounds showed the effects of improving insulin-stimulated glucose consumption in differentiated 3T3-L1 adipocytes compared with the control group. Especially, 2-hydroxy-1-methoxyaporphine (A) and pronuciferine (B) exhibited the most potent glucose consumption-stimulatory activity at the concentration of $2 \mu \mathrm{g} / \mathrm{mL}$. The glucose consumption were 12.29 and $11.88 \mathrm{mmol} / \mathrm{L}$ respectively, which were similar with the $11.2 \mathrm{mmol} / \mathrm{L}$ of the positive control $(1 \mu \mathrm{mol} / \mathrm{L}$ rosiglitazone $)$. It has been found that an analogue of these four aporphine alkaloid, possesses variable beneficial bioactivities including antioxidation in diabetic rats [28], up-regulating the adiponectin expression in 3T3-L1 cells [29] and improvement the endothelial function in spontaneously hypertensive rats [30]. Moreover, the adiponectin could upregulate the glucose uptake in adiopocytes through the activation of AMP-activated protein kinase (AMPK) [31]. These suggest that the AMPK signal pathway might mediate the glucose consumption of the two aporphine alkaloids. Moreover, the effects of 
2-hydroxy-1-methoxyaporphine (A) and pronuciferine (B) on glucose consumption might be due to their strong polarity as shown in Figure 3.

Figure 5. Cytotoxicity effect of aporphine alkaloids on 3T3-L1 cells. A: 2-hydroxy-1methoxyaporphine; B: pronuciferine; C: nuciferine; D: roemerine.

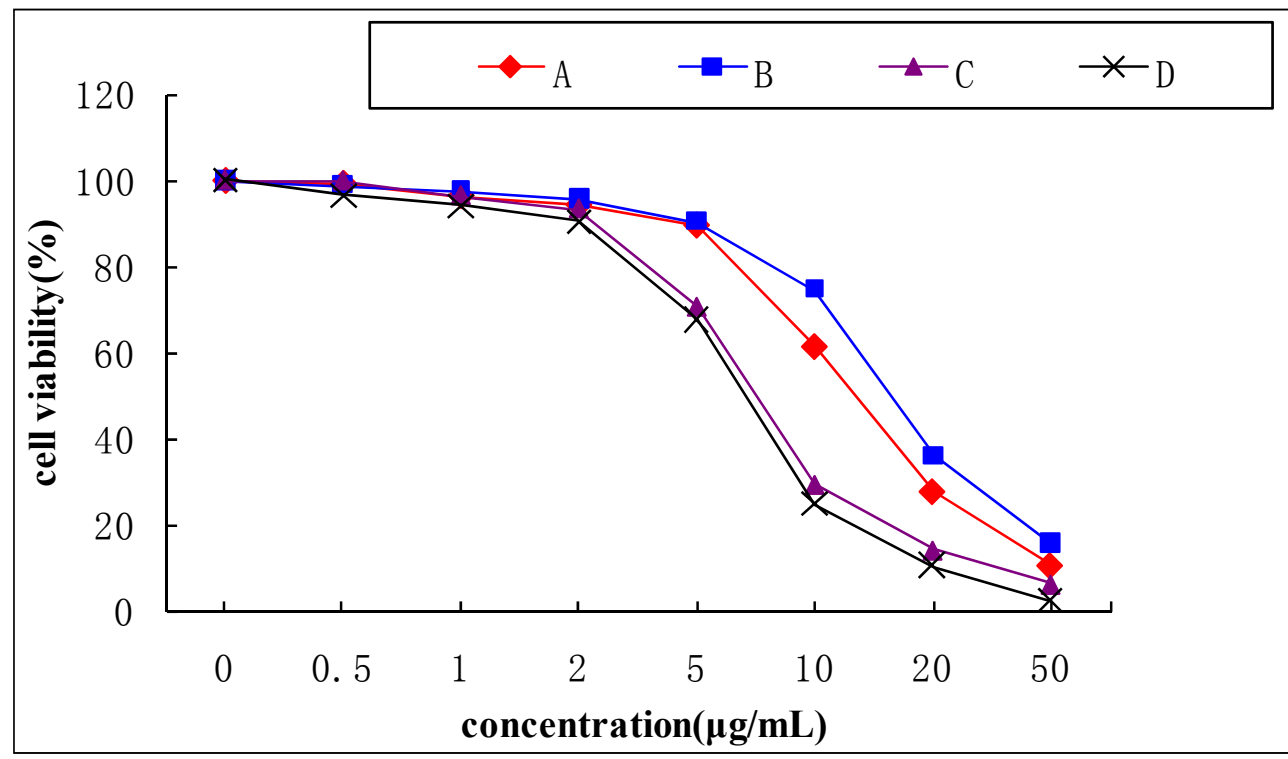

Figure 6. Effects of aporphine alkaloids on glucose consumption in differentiated 3T3-L1 adipocytes. The glucose consumption effect of $1 \mu \mathrm{mol} / \mathrm{L}$ rosiglitazone (Rosi.) as a positive control (Rosi. vs. control, $p<0.01$ ). Data are the mean $\pm \mathrm{SD}, n=3$. ${ }^{*} p<0.05 ; * * p<0.01$ $v s$. control group. A: 2-hydroxy-1-methoxyaporphine; B: pronuciferine; C: nuciferine; D: roemerine.

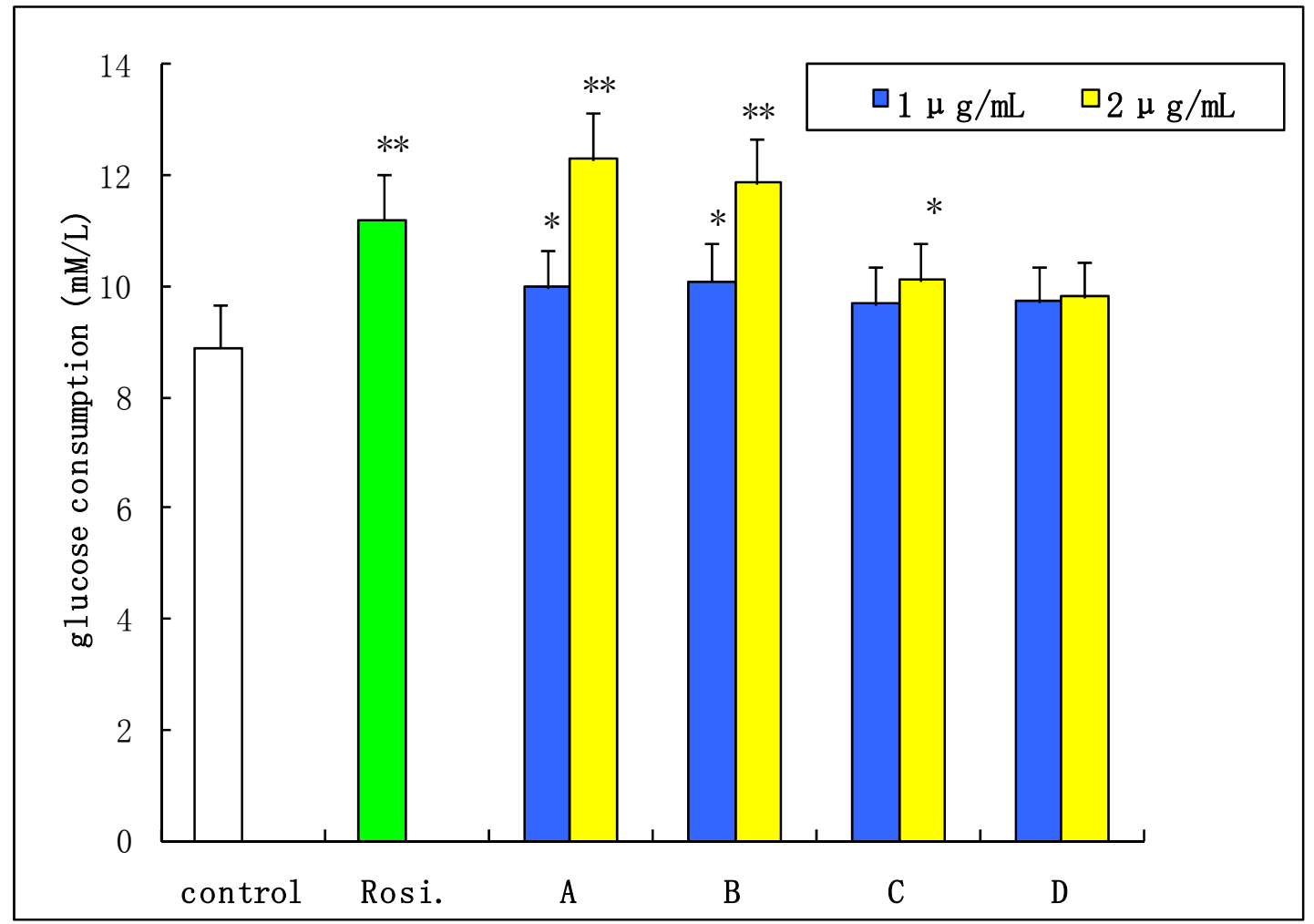




\section{Experimental Section}

\subsection{Chemical and Reagents}

The leaves of $N$. nucifera were purchased from Yantai Chinese drug store (Yantai, China). Chloroform, $n$-hexane, ethyl acetate, and methanol were obtained from Yantai huada reagent Co. Inc. (Yantai, China). HPLC-grade methanol, acetonitrile were obtained from Tedia Company Inc. (Fairfield, CA, USA). Reverse osmosis Milli-Q water (18 M $\Omega$ ) (Bedford, MA, USA) was used for all solutions and dilution. 3T3-L1 cells were obtained from the cell bank of the Institute of Biochemistry and Cell Biology (Shanghai, China). Phosphate buffered saline (PBS), DMEM medium; calf serum (CS), fetal bovine serum (FBS), penicillin-streptomycin solution and trypsin-EDTA solution were purchased from GIBCO Co. Inc. (Beijing Representative Office, Beijing, China). 3-(4,5-dimethylthiazol-2-yl)-2,5-diphenyltetrazolium bromide (MTT) and Oil Red O were purchased from Sigma-Aldrich Co. Inc. (Milwaukee, WI, USA).

\subsection{Apparatus}

HSCCC was performed using a Model TBE-300A HSCCC system (Shanghai Tauto Biotech Co., Ltd., Shanghai, China), equipped with a $280 \mathrm{~mL}$ coil column made of polytetrafluoroethylene tubing (I.D. of the tubing $=1.8 \mathrm{~mm}$ ). The $\beta$-value of the preparative column varied from 0.42 at the internal layer to 0.63 at the external layer $(\beta=r / R$, where $r$ is the distance from the coil to the holder shaft, and $R$ is the revolution radius or the distance between the holder axis and central axis of centrifuge. For this apparatus, the revolution radius is $130 \mathrm{~mm}$ ). The revolution speed of the apparatus could be adjusted in a range between 0 and $900 \mathrm{rpm}$. The solvent was pumped into the column by a Model S 1007 constant-flow pump (Beijing Shengyitong Technology Development Co., Ltd., Beijing, China), and continuously delivered by $270 \mathrm{~nm}$ absorption with a Model TSP $1000 \mathrm{UV}$ detector (TSP, Waltham, MA, USA), the data was displayed and analyzed simultaneously on a Model Anastar 2.0 chromatographic data workstation (Tianjin Autoscience Instrument Co., Ltd., Tianjin, China). A manual injection valve with a $20 \mathrm{~mL}$ loop was used to introduce the sample into the column.

The analytical HPLC system used throughout this study was Agilent 1100 HPLC system including G 1311A pump, G1315B UV-vis detector and Agilent HPLC workstation (Agilent Technologies, Waldbronn, Germany), with a reversed-phase Discovery C18 column $(25 \mathrm{~cm} \times 4.6 \mathrm{~mm}$ I.D., $5 \mu \mathrm{m}$; Sigma-Aldrich, Bellefonte, PA, USA).

\subsection{Preparation of Crude Extract from the Leaves of N. nucifera}

The leaves of $N$. nucifera were dried at $60{ }^{\circ} \mathrm{C}$ and pulverized. $300 \mathrm{~g}$ of sample were extracted three times with $0.1 \mathrm{~mol} / \mathrm{L}$ hydrochloric $(3000 \mathrm{~mL} \times 3)$ under $40,000 \mathrm{~Hz}$ of ultrasonic for $20 \mathrm{~min}$ each time. All extracting solution was combined, filtrated and $0.1 \mathrm{~mol} / \mathrm{L}$ sodium hydrate was added into the filtrated until the $\mathrm{pH}$ of the solution reached 8.5 , filtrated by filter paper. Then, the solutions were evaporated under reduced pressure and $60{ }^{\circ} \mathrm{C}$ to dryness, which yielded $2.1 \mathrm{~g}$ of crude alkaloid extracts for subsequent HSCCC separation. 


\subsection{Selection of Two-Phase Solvent Systems and Sample Solution for HSCCC}

A number of two-phase solvent systems were tested by changing the volume of the solvent to obtain the optimum composition that gave suitable partition coefficient $(K)$ values. The partition coefficient values were determined according to the literature [23,32]. In brief, approximately $4.0 \mathrm{mg}$ sample of crude extracts were weighed in a $10 \mathrm{~mL}$ test tube to which $3 \mathrm{~mL}$ of each phase of the pre-equilibrated two-phase solvent system was added. After the tube was shaken vigorously for $1 \mathrm{~min}$, the solution was quietly separated for a moment. Then, the upper and lower phases were analyzed by HPLC to obtain the partition coefficient $(K)$ of four targeted compounds respectively. The $K$ value was calculated as follows:

$$
K=\frac{\text { HPLC peak area of solute in upper phase }}{\text { HPLC peak area of solute in lower phase }}
$$

The selected solvent system ( $n$-hexane-ethyl acetate-methanol-acetonitrile-water) was thoroughly equilibrated by repeatedly vigorously shaking in a separation funnel at room temperature. Two phases were separated shortly and degassed before use. The volume ratio of the five solvents is 5:3:3:2.5:5 $(v / v / v / v / v)$. The upper phase was used as the stationary phase, while the lower phase was used as the mobile phase.

The sample solutions were prepared by dissolving the crude extract in the mixture solution of upper phase and lower phase $(1: 1, v / v)$ of the solvent system used for HSCCC separation.

\subsection{HSCCC Separation Procedure}

In each separation, the multiplayer-coil column was first entirely filled with the upper phase (stationary phase). The lower phase (mobile phase) was then pumped into the head end of the inlet column at a flow rate of $2.0 \mathrm{~mL} / \mathrm{min}$, while the apparatus was rotated at $850 \mathrm{rpm}$. After reaching hydrodynamic equilibrium, as indicated by a clear mobile phase eluting at the tail outlet, the sample solution (100 mg of the crude extract in $12 \mathrm{~mL}$ of the total volume of both phase that is 1:1) was injected into the column through the sample port. The effluent from the tail end of the column was continuously monitored with a UV detector at $270 \mathrm{~nm}$ as stated earlier and the chromatogram was recorded. Each peak fraction was collected manually according to the elution profile and determined by HPLC.

\subsection{HPLC Analysis and Identification of HSCCC Fractions}

The mobile phase was acetonitrile-water-triethylamine-glacial acetic acid (55:44:1:0.15, v/v/v/v) and the flow rate was $1.0 \mathrm{~mL} / \mathrm{min}$. A sample volume of $20 \mu \mathrm{L}$ was injected. The crude sample and peak fractions obtained by HSCCC were analyzed by HPLC. The identification of HSCCC peak fractions was carried out by MS on mass spectrometer and by ${ }^{1} \mathrm{H}$ NMR and ${ }^{13} \mathrm{C}$ NMR spectra. 


\subsection{T3-L1 Cell Culture}

T3-L1 cells were cultured in DMEM medium with $10 \%$ calf serum $(\mathrm{CS}), 1.5 \mathrm{~g} / \mathrm{L}$ of sodium bicarbonate and $1 \%$ penicillin-streptomycin solution. Cells were cultured at $37{ }^{\circ} \mathrm{C}$ in a humidified atmosphere containing $5 \% \mathrm{CO}_{2}$ and medium was replaced every other day until confluent.

\subsection{Cytotoxicity Study of Aporphine Alkaloids}

In vitro cell viability was measured using the MTT assay. Briefly, following the treatment of cells in 96-well plate $\left(4 \times 10^{4}\right.$ cells/well) with different concentrations of aporphine alkaloids in DMEM containing 10\% FBS for $20 \mathrm{~h}$, the cells were incubated with MTT solution $(0.5 \mathrm{mg} / \mathrm{mL})$ for $4 \mathrm{~h}$ at $37{ }^{\circ} \mathrm{C}$. The formation of a violet precipitate formazan was monitored at a wavelength of $490 \mathrm{~nm}$ with a Bio-Rad 550 microplate reader (Hercules, CA, USA).

\subsection{Insulin-Stimulated Glucose Consumption Study}

Insulin resistance was induced in 3T3-L1 cells as reference described with minor modifications [27]. Briefly, 2 day-post-confluent preadipocytes (day 0) were cultured in 10\% FBS/DMEM medium containing $0.5 \mathrm{mmol} / \mathrm{L}$ isobutylmethylxanthine (IBMX), $1 \mu \mathrm{mol} / \mathrm{L}$ dexamethasone and $10 \mu \mathrm{g} / \mathrm{mL}$ insulin for 2 days. The cells were further incubated in the growth medium containing $1 \mu \mathrm{g} / \mathrm{mL}$ insulin for additional 2 days, and thereafter medium was replaced with fresh growth media, which was changed every 2 days thereafter until the cells were fully differentiated. Over $95 \%$ of the preadipocytes differentiated into adipocytes by day 8 , as determined by Oil Red $\mathrm{O}$ staining. Then, the 3T3-L1 adipocytes were plated in 96-well plates in DMEM containing 10\% FBS and $1 \mu \mathrm{mol} / \mathrm{L}$ dexamethasone. The tested compounds were added for an additional 2 days. The glucose content in culture medium was measured by glucose oxidase method and glucose consumption was calculated.

\section{Conclusions}

In conclusion, our present finding is the first report on separation and purification of four aporphine alkaloids including 2-hydroxy-1-methoxyaporphine, pronuciferine, nuciferine, and roemerine from lotus leaves by HSCCC using the new two-phase solvent system on one step. Through the insulin-resistance 3T3-L1 adipocytes, we evaluated the glucose consumption-stimulatory activity of purified compounds. The overall results of the present study indicate that HSCCC is a powerful technique in separating and purifying bioactive compounds from natural sources. All the four compounds possessed concentration-dependent cytotoxicity in 3T3-L1 cells in which 2-hydroxy-1-methoxyaporphine and pronuciferine powerfully enhanced the glucose consumption in adipocytes differentiated from 3T3-L1 cells as rosiglitazone did. These finding may be benefit for the popular use of lotus leaves in blood sugar balance and weight loss in China. 


\section{Acknowledgments}

This project is supported in part by the Natural Science Foundation of China (21372190, 81001698), the excellent young Scientists award of Shandong province, China (2006BS01226, BS2012YY039), and the Natural Science Foundation of Shandong province, China (2009ZRB019XL).

\section{Conflicts of Interest}

The authors declare no conflict of interest.

\section{References}

1. Wu, S.H.; Sun, C.R.; Cao, X.J.; Zhou, H.; Zhang, H.; Pan, Y.J. Preparative counter-current chromatography isolation of liensinine and its analogues from embryo of the seed of Nelumbo nucifera Gaertn using upright coil planet centrifuge with four multilayer coils connected in series. J. Chromatogr. A 2004, 1041, 153-162.

2. China Pharmacopoeia Committee. Pharmacopoeia of the Peoples' Republic of China; China Chemical Industry Press: Beijing, China, 2010; pp. 256-258, 358.

3. Nakamura, S.; Nakashima, S.; Tanabe, G.; Oda, Y.; Yokota, N.; Fujimoto, K.; Matsumoto, T.; Sakuma, R.; Ohta, T.; Ogawa, K.; et al. Alkaloid constituents from flower buds and leaves of sacred lotus (Nelumbo nucifera, Nymphaeaceae) with melanogenesis inhibitory activity in B16 melanoma cells. Bioorg. Med. Chem. 2013, 21, 779-789.

4. Xiao, G.Q.; Lu, X.Y.; Tian, Y.; Yi, K.; Zhou, X.M. The research advance of alkaloids from lotus leaf. Chem. Bioen. 2006, 23, 1-2.

5. Luo, X.; Chen, B.; Liu, J.; Yao, S. Simultaneous analysis of $N$-nornuciferine, $O$-nornuciferine, nuciferine, and roemerine in leaves of Nelumbo nucifera Gaertn by high-performance liquid chromatography-photodiode array detection-electrospray mass spectrometry. Anal. Chim. Acta 2005, 538, 129-133.

6. Wang, L.L.; Liu, B.; Shi, R.B. Study on chemical constituents of folium nelumbinis. Nat. Prod. Res. Dev. 2009, 21, 416-419.

7. Yang, Z.D.; Zhang, X.; Du, J.; Ma, Z.J.; Guo, F.; Li, S.; Yao, X.J. An aporphine alkaloid from Nelumbo nucifera as an acetylcholinesterase inhibitor and the primary investigation for structure-activity correlations. Nat. Prod. Res. 2012, 26, 387-392.

8. Kashiwada, Y.; Aoshima, A.; Ikeshiro, Y.; Chen, Y.P.; Furukawa, H.; Itoigawa, M.; Fujioka, T.; Mihashi, K.; Cosentino, L.M.; Morris-Natschke, S.L.; et al. Anti-HIV benzylisoquinoline alkaloids and flavonoids from the leaves of Nelumbo nucifera, and structure-activity correlations with related alkaloids. Bioorg. Med. Chem. 2005, 13, 443-448.

9. Lacour, B.; Molgaard, P.; Yi, Z. Traditional Chinese medicine in treatment of heperlipidemia. J. Ethnopharmacol. 1995, 46, 125-129.

10. Chen, K.S.; Ko, F.N.; Teng, C.M.; Wu, Y.C. Antiplatelet and vasorelaxing actions of some benzylisoquinoline and phenanthrene alkaloids. J. Nat. Prod. 1996, 59, 531-534. 
11. Morales, M.A.; Bustamante, S.E.; Brito, G.; Pazd, D.; Cassels, B.K. Cardiovascular effect of plant secondary metabolites norarmepavine, coclaurine and norcoclaurine. Phytother. Res. 1998, 12, 103-109.

12. Cho, E.J.; Yokozawa, T.; Rhyu, D.Y.; Kim, S.C.; Shibahara, N.; Park, J.C. Study on the inhibitory effects of Korean medicinal plant and their main compounds on the 1,1-diphenyl-2-picrylhydrazy radical. Phytomedicine 2003, 10, 544-551.

13. Agnihotri, V.K.; Elsohly, H.N.; Khan, S.I.; Jacob, M.R.; Joshi, V.C.; Smillie, T.; Khan, I.A.; Walker, L.A. Constituents of Nelumbo nucifera leaves and their antimalarial and antifungal activity. Phytochem. Lett. 2008, 1, 89-93.

14. Ohkoshi, E.; Miyazaki, H.; Shindo, K.; Watanabe, H.; Yoshida, A.; Yajima, H. Constituents from the leaves of Nelumbo nucifera stimulate lipolysis in the white adipose tissue of mice. Planta Med. 2007, 73, 1255-1259.

15. Ono, Y.; Hattori, E.; Fukaya, Y.; Imai, S.; Ohizumi, Y. Anti-obesity effect of Nelumbo nucifera leaves extract in mice and rats. J. Ethnopharmacol. 2006, 106, 238-244.

16. Nguyen, K.H.; Ta, T.N.; Pham, T.H.; Nguyen, Q.T.; Pham, H.D.; Mishra, S.; Nyomba, B.L. Nuciferine stimulates insulin secretion from beta cells-an in vitro comparison with glibenclamide. J. Ethnopharmacol. 2012, 142, 488-495.

17. Do, T.C.; Nguyen, T.D.; Tran, H.; Stuppner, H.; Ganzera, M. Analysis of alkaloids in Lotus (Nelumbo nucifera Gaertn.) leaves by non-aqueous capillary electrophoresis using ultraviolet and mass spectrometric detection. J. Chromatogr. A 2013, 1302, 174-180.

18. Ahn, J.H.; Kim, E.S.; Lee, Ch.; Kim, S.; Cho, S.H.; Hwang, B.Y.; Lee, M.K. Chemical constituents from Nelumbo nucifera leaves and their anti-obesity effects. Bioorg. Med. Chem. Lett. 2013, 23, 3604-3608.

19. Chen, J.; Ma, X.; Gao, K.; Wang, Y.; Zhao, H.; Wu, H.; Wang, J.; Xie, H.; OuYang, Y.; Luo, L.; et al. The active ingredients of Jiang-Zhi-Ning: Study of the Nelumbo nucifera alkaloids and their main bioactive metabolites. Molecules 2012, 17, 9855-9867.

20. Ito, Y. Golden rules and pitfalls in selecting optimum conditions for high-speed counter-current chromatography. J. Chromatogr. A 2005, 1065, 145-168.

21. Fang, L.; Liu, Y.; Yang, B.; Wang, X.; Huang, L. Separation of alkaloids from herbs using high-speed counter-current chromatography. J. Sep. Sci. 2011, 34, 2545-2558.

22. Zheng, Z.J.; Wang, M.L.; Wang, D.J.; Duan, W.J.; Wang, X.; Zheng, C.C. Preparative separation of alkaloids from Nelumbo nucifera leaves by conventional and Ph-zone-refining counter-current chromatography. J. Chromatogr. B 2010, 878, 1647-1651.

23. Inoue, K.; Nomura, C.; Ito, S.; Nagatsu, A.; Hino, T.; Oka, H. Purification of curcumin, demethoxycurcumin, and bisdemethoxycurcumin by high-speed countercurrent chromatography. J. Agric. Food Chem. 2008, 56, 9328-9336.

24. Li, Z.C.; Zuo, C.X.; Yang, S.J.; Zhong, Y.; Ding, X.B. Study on chemical constituents of folium nelumbinis. Chin. Tradit. Herb. Drugs 1996, 27, 50-52.

25. Wu, H.; Liu, B.; Wang, W.; Shi, R.B. Studies on the chemical reference substance 2-hydroxy-1methoxyaporphine of folium nelumbinis. Chin. J. Pharm. Anal. 2010, 30, 1650-1653. 
26. Xu, M.E.; Xiao, S.Z.; Sun, Y.H.; Ou-yang, Y.; Guan, C.; Zheng, X.X. A preadipocyte differentiation assay as a method for screening potential anti-type II diabetes drugs from herbal extracts. Planta Med. 2006, 72, 14-19.

27. Saltiel, A.R.; Kahn, C.R. Insulin signalling and the regulation of glucose and lipid metabolism. Nature 2001, 414, 799-806.

28. Jang, Y.Y.; Song, J.H.; Shin, Y.K.; Han, E.S.; Lee, C.S. Protective effect of boldine on oxidative mitochondrial damage in streptozotocin-induced diabetic rats. Pharmacol. Res. 2000, 42, 361-371.

29. Yu, B.; Cook, C.; Santanam, N. The aporphine alkaloid boldine induces adiponectin expression and regulation in 3T3-L1 cells. J. Med. Food 2009, 12, 1074-1083.

30. Lau, Y.S.; Tian, X.Y.; Mustafa, M.R.; Murugan, D.; Liu, J.; Zhang, Y.; Lau, C.W.; Huang, Y. Boldine improves endothelial function in diabetic $\mathrm{db} / \mathrm{db}$ mice through inhibition of angiotensin II-mediated BMP4-oxidative stress cascade. Br. J. Pharmacol. 2013, doi:10.1111/bph.12350.

31. Wu, X.; Motoshima, H.; Mahadev, K.; Stalker, T.J.; Scalia, R.; Goldstein, B.J. Involvement of AMP-activated protein kinase in glucose uptake stimulated by the globular domain of adiponectin in primary rat adipocytes. Diabetes 2003, 52, 1355-1363.

32. Ma, C.J.; Li, G.; Zhang, J.; Zheng, Q.S.; Fan, X.; Wang, Z.H. An efficient combination of supercritical fluid extraction and high-speed counter-current chromatography to extract and purify homoisoflavonoids from Ophiopogon japonicas (Thunb.) Ker-Gawler. J. Sep. Sci. 2009, 32, 1949-1956.

(C) 2014 by the authors; licensee MDPI, Basel, Switzerland. This article is an open access article distributed under the terms and conditions of the Creative Commons Attribution license (http://creativecommons.org/licenses/by/3.0/). 